\title{
Charting ELSI's future course: lessons from the recent past
}

\author{
Rebecca L. Walker, $\mathrm{PhD}^{1}$ and Clair Morrissey, $\mathrm{PhD}^{2}$
}

Purpose: We sought to examine the ethical, legal, and social implications (ELSI) literature research and scholarship types, topics, and contributing community fields of training as a first step to charting the broader ELSI community's future priorities and goals.

Methods: We categorized 642 articles and book chapters meeting inclusion criteria for content in both human genetics or genomics and ethics or ELSI during a 5-year period (2003-2008) according to research and scholarship types, topics, and the area of advanced training of the first-listed author. Research and scholarship type categories were developed and characterized through in-depth review of 95 randomly sampled publications from the larger group.

Results: There is a single dominant approach to ELSI, which focuses on ethical and other social issues "downstream" of advances in genomics, the contributors to which predominately have advanced training in medicine or science fields other than social science.
A comparatively low percentage of publications primarily offer policy recommendations, and these are much more likely to be written by those with advanced training in law than is the case for the literature as a whole. Social science studies predominately employ qualitative methods and vary significantly with respect to the extent and types of recommendations offered. Two further types of ELSI research and scholarship offer alternative models for so-called "normative" work in this field.

Conclusion: Considering topics, training, and types of ELSI research and scholarship from the most recent past allows for a baseline perspective that is sorely needed in charting this field's future course.

Genet Med 2012:14(2):259-267

Key Words: ELSI research; ethics; human genetics; human genomics; NHGRI

\section{INTRODUCTION}

The phrase "ethical, legal, and social implications" (ELSI) derives from the Ethical, Legal and Social Implications Research Program of the US National Institutes of Health's National Human Genome Research Institute (NHGRI). However, the community of ELSI researchers, understood as those investigating issues at the intersection of socially relevant concerns and human genomics, is much wider than those researchers supported by the National Institutes of Health or even by international counterparts. Just as we would not want to understand what counts as genomics research in terms of funding sources, we should not limit the boundaries of the ELSI community artificially by conflating this maturing field of research and scholarship with a particular government program. Indeed, although most acknowledged funding for ELSI research is from the National Institutes of Health, only a little more than a third of ELSI publications acknowledge any funding (C. Morrissey and R.L. Walker, Funding and Forums for ELSI Reaserch, unpublished data).

Yet while the NHGRI has drawn upon the larger genomics community in putting forth its visions for the future of genomics research, including ELSI research, the wider ELSI community has not similarly engaged in a process of envisioning future ELSI research priorities and goals. With the February 2011 publication of the newest strategic vision for genomics research, ${ }^{1}$ it may be time for ELSI as a maturing field encompassing a broad and diverse community to take a look at itself in contributing to charting its future course. However, to complete this task, the field needs a robust understanding of the research and scholarship contributions and literature in its most recent past.

Our research investigated literature at the intersection of ethics or ELSI and human genetics or genomics published between 2003 and 2008, the 5-year period immediately preceding the start of our project. In this article, we present a detailed account of the different types of research and scholarship appearing at this intersection as well as the topics addressed and the fields in which publication first-listed authors had advanced training. Elsewhere, we report in detail on findings regarding funding sources and publication venues (C. Morrissey and R.L. Walker, Funding and Forums for ELSI Reaserch, unpublished data).

\section{MATERIALS AND METHODS}

We collected publications addressing the intersection of ethics specifically or ELSI more broadly and human genetics or genomics released within the 5-year period from 2003 to 2008. In order to represent the research and scholarship of the wider ELSI community, we utilized multiple sources capturing (i) the work of people closely identified with the ELSI Research Program through the ELSI Archives (created by Case Western Reserve University's Center for Genetic Research Ethics and Law), 
the Bio-Medical Ethics Reference Server (hosted by Stanford University's Center for Integration of Research on Genetics and Ethics), and all other Centers for Excellence in ELSI Research web pages; (ii) research from more broadly medical, social, and other science researchers through PubMed and Web of Science; and (iii) the work of humanities researchers and scholars (in particular, book chapters) through the GenETHX database (hosted by the Bioethics Research Library at Georgetown University).

The multiplicity of sources dictated some variation in the search strategies. A narrowly tailored Boolean search was used for PubMed, Web of Science, and GenETHX; a key-word search was used for the Bio-Medical Ethics Reference Server; all of the references from the Centers for Excellence in ELSI Research web pages were collected, and the ELSI Archives were searched by hand for relevant publications. Search terms included variants and combinations of the terms "ethics," "morality," "ELSI," "genomics," and "genetics." Specific search strategies were developed with the help of health sciences research librarians at the authors' home institution as well as from the Georgetown Bioethics Research Library. Although our publication collection strategy was inclusive in terms of diverse contributors to the ELSI literature, ELSI-relevant publications released during our 5-year period that did not employ the terms "ethics," "morality," or "ELSI" and were not included in the ELSI databases or web pages consulted are not represented in this study.

The flow chart in Figure 1 tracks the inclusion/exclusion processes, which generated the final group of 642 articles and book chapters from the initial group of 1,010 publications collected. All English-language publications addressing human genetics or genomics and ethics or other ELSI that were book chapters, research/scholarship articles, or other substantial contributions to the literature (e.g., commentaries and, infrequently, editorials) were included in the study. No topics were excluded except those that did not specifically address human genetics/genomics.

All 642 publications were classified according to topic addressed, field of advanced training of the first-listed author, and one of five research and scholarship types. Topics were developed using the session headings for the 2008 ELSI Congress, "Translating ELSI: Global Perspectives in Research on the Ethical, Legal, and Social Implications of Human Genome Research," held during May 1-3 in Cleveland, Ohio. Additional topics were added, and others conflated as necessary to adequately reflect the literature. First-listed author field of advanced training was determined according to information either available in the publication itself or from an institutional or individual website associated with the author. The five types

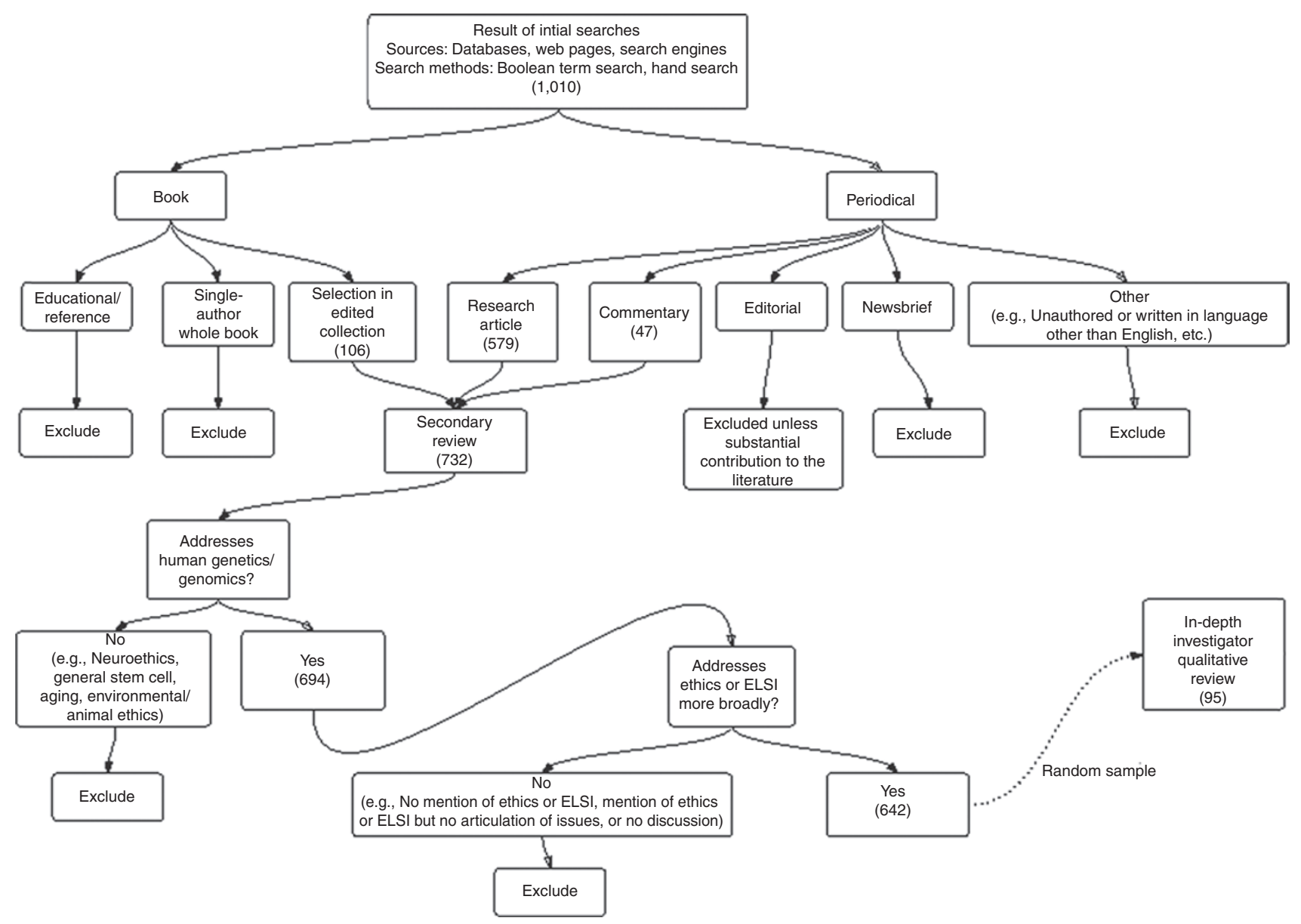

Figure 1 Identification of publications used in this study. ELSI, ethical, legal, and social implications. 
employed for organizing the literature were developed through an in-depth analysis of 95 randomly sampled publications from the larger group. The titles we chose to reflect these types are: social science study report, broader ELSI, ethics focus, other normative focus, and policy recommendation. The particular features of each type of research as well as the interactions with topics and first-author fields of training are presented below.

\section{ELSI topics}

\section{RESULTS}

Twenty-two topics, each accounting for between $1 \%$ and $9 \%$ of the ELSI literature, are listed in Table 1. Also listed in Table 1 are interactions with the research and scholarship types that we discuss below. The most common topic was not any particular subtopic within genetics or genomics, but rather genetics or genomics generally. Authors addressing this topic may have referred to "the new genomics" or broadly "advances in genomics." This topic was added to those delineated by the 2008 ELSI Congress session headings in order to accommodate the literature in our study. Additional categories that were added are "other," which included topics as diverse as behavioral genetics, chimeras, and cancer genomics, and "other genomic research," "other genetic testing," and "other reproductive genetics," which were necessary to capture either a general focus on genetic testing, research, or reproductive genetics or particular subjects falling under these broader headings that were not represented elsewhere in the list.

\section{ELSI community}

To identify fields of advanced training within the ELSI community as well as international representation within our study, we located institutional affiliations of first- (or sole-) listed authors as well as first- (or sole-) listed author advanced degrees. Advanced degrees were categorized according to the fields presented along the top of Table 2. The institutional affiliations of authors represented in our study indicate a transnational research community. Rounding to the nearest percentage, $67 \%$ of first authors had primary institutional affiliations in North America, 25\% in Europe, and 3\% each in Asia and Australasia. One percent of authors were international bodies. There were no publications in which the first-listed author's primary institutional affiliation was in Africa or Central America.

Table 2 organizes first-listed author field of training according to the research and scholarship types discussed in more detail below; however, total numbers for authors with advance degrees in each field is a simple sum of each column. The most prevalent fields of study were humanities (including theology) (28\%); medicine (defined as all fields contributing to clinical care) (19\%); social science (18\%); basic, natural, or medical science (18\%); and law (17\%). A noteworthy proportion of first authors (20\%) had advanced training in multiple fields; therefore, the total number of publications for all fields combined is greater than $>100 \%$.

\section{Types}

Research and scholarship types to organize and enhance understanding of the ELSI work represented in our study were
Table 1 Dominant publication types for each ELSI topic

\begin{tabular}{lcclc} 
Topic & $\boldsymbol{N = 6 4 2}$ & \% Total & $\begin{array}{l}\text { Dominant } \\
\text { type }\end{array}$ & \% Topic \\
\hline $\begin{array}{l}\text { Genomics, } \\
\text { general }\end{array}$ & 58 & $9 \%$ & $\begin{array}{l}\text { Other } \\
\text { normative }\end{array}$ & $40 \%$ \\
\hline Biorepository & 49 & $8 \%$ & Broader ELSI & $55 \%$ \\
Genetics and race & 45 & $7 \%$ & $\begin{array}{l}\text { Other } \\
\text { normative }\end{array}$ & $47 \%$ \\
\hline
\end{tabular}

Genetic

\begin{tabular}{|c|c|c|c|c|}
\hline enhancement & 44 & $7 \%$ & Ethics & $66 \%$ \\
\hline $\begin{array}{l}\text { Genomic research } \\
\text { and the public }\end{array}$ & 40 & $6 \%$ & Empirical & $60 \%$ \\
\hline $\begin{array}{l}\text { Intellectual } \\
\text { property }\end{array}$ & 38 & $6 \%$ & $\begin{array}{l}\text { Other } \\
\text { normative }\end{array}$ & $50 \%$ \\
\hline $\begin{array}{l}\text { Personalized } \\
\text { health } \\
\text { interventions }\end{array}$ & 29 & $5 \%$ & Broader ELSI & $62 \%$ \\
\hline $\begin{array}{l}\text { Genomics and } \\
\text { clinical practice }\end{array}$ & 29 & $5 \%$ & Broader ELSI & $62 \%$ \\
\hline $\begin{array}{l}\text { Human subject } \\
\text { protection }\end{array}$ & 24 & $4 \%$ & Policy & $38 \%$ \\
\hline \multirow[t]{2}{*}{ Informed consent } & 24 & $4 \%$ & Empirical & $38 \%$ \\
\hline & & & Broader ELSI & $38 \%$ \\
\hline Prenatal testing & 18 & $3 \%$ & Empirical & $44 \%$ \\
\hline $\begin{array}{l}\text { Return of research } \\
\text { results }\end{array}$ & 15 & $2 \%$ & Broader ELSI & $47 \%$ \\
\hline $\begin{array}{l}\text { Gene transfer } \\
\text { research }\end{array}$ & 14 & $2 \%$ & Broader ELSI & $71 \%$ \\
\hline $\begin{array}{l}\text { GWAS or } \\
\text { whole-genome } \\
\text { sequencing }\end{array}$ & 13 & $2 \%$ & Broader ELSI & $69 \%$ \\
\hline $\begin{array}{l}\text { Genomic } \\
\text { research in native } \\
\text { communities }\end{array}$ & 13 & $2 \%$ & $\begin{array}{l}\text { Other } \\
\text { normative }\end{array}$ & $54 \%$ \\
\hline $\begin{array}{l}\text { Genomics and } \\
\text { health disparities }\end{array}$ & 12 & $2 \%$ & Broader ELSI & $42 \%$ \\
\hline $\begin{array}{l}\text { Newborn } \\
\text { screening }\end{array}$ & 9 & $1 \%$ & Policy & $56 \%$ \\
\hline \multirow{2}{*}{$\begin{array}{l}\text { Genetic } \\
\text { counseling }\end{array}$} & 9 & $1 \%$ & Broader ELSI & $55 \%$ \\
\hline & & & Empirical & $45 \%$ \\
\hline $\begin{array}{l}\text { Other genomic } \\
\text { research }\end{array}$ & 49 & $8 \%$ & Broader ELSI & $45 \%$ \\
\hline $\begin{array}{l}\text { Other genetic } \\
\text { testing }\end{array}$ & 46 & $7 \%$ & Broader ELSI & $50 \%$ \\
\hline \multirow{2}{*}{$\begin{array}{l}\text { Other } \\
\text { reproductive } \\
\text { genetics }\end{array}$} & 24 & $4 \%$ & Broader ELSI & $33 \%$ \\
\hline & & & $\begin{array}{l}\text { Other } \\
\text { normative }\end{array}$ & $33 \%$ \\
\hline Other & 40 & $6 \%$ & Broader ELSI & $48 \%$ \\
\hline
\end{tabular}

ELSI, ethical, legal, and social implications; GWAS, genome-wide association study.

developed through an iterative process of in-depth review and analysis of 95 publications randomly sampled from the larger group. The types represent nexuses of methodological, conceptual, and practical or theoretical focuses within the publications. Type definitions, frequencies within the study as a whole, 
Table 2 Frequencies of first-author disciplines for each ELSI publication type

\begin{tabular}{|c|c|c|c|c|c|c|c|c|c|}
\hline \multirow[b]{2}{*}{ Type } & \multicolumn{9}{|c|}{ First-author field ${ }^{a}$} \\
\hline & Bioethics & Business & Humanities & Law & Medicine & $\begin{array}{l}\text { Other } \\
\text { science }\end{array}$ & $\begin{array}{l}\text { Public } \\
\text { health }\end{array}$ & $\begin{array}{c}\text { Social } \\
\text { science }\end{array}$ & $\begin{array}{c}\text { Not } \\
\text { applicable }\end{array}$ \\
\hline $\begin{array}{l}\text { Social science } \\
\text { study report } \\
(n=108)\end{array}$ & $5(5 \%)$ & $0(0 \%)$ & $15(14 \%)$ & $4(4 \%)$ & $24(22 \%)$ & $14(13 \%)$ & $20(19 \%)$ & $44(41 \%)$ & $0(0 \%)$ \\
\hline $\begin{array}{l}\text { Broader ELSI } \\
(n=239)\end{array}$ & $3(1 \%)$ & $5(2 \%)$ & $43(18 \%)$ & $31(13 \%)$ & $71(30 \%)$ & $62(26 \%)$ & $20(8 \%)$ & $33(14 \%)$ & $1(<1 \%)$ \\
\hline $\begin{array}{l}\text { Other normative } \\
\text { frame }(n=127)\end{array}$ & $4(3 \%)$ & $2(2 \%)$ & $48(38 \%)$ & $29(23 \%)$ & $15(12 \%)$ & $14(11 \%)$ & $3(2 \%)$ & $24(19 \%)$ & $0(0 \%)$ \\
\hline $\begin{array}{l}\text { Policy } \\
\text { recommendation } \\
(n=66)\end{array}$ & $2(3 \%)$ & $1(2 \%)$ & $10(15 \%)$ & $26(39 \%)$ & $4(6 \%)$ & $7(11 \%)$ & $12(18 \%)$ & $6(9 \%)$ & $8(12 \%)$ \\
\hline
\end{tabular}

ELSI, ethical, legal, and social implications.

aFirst author has at least one advanced degree in the specified academic field of study. Among first authors, $20 \%$ have advanced training in more than one field of study. The discipline for $7 \%$ of first authors was either unknown (could not be located) or unspecified (PhD, but field not specified). "Not applicable" refers to authorship by an institutional body.

Table 3 ELSI type definitions, frequencies, and sample quotes

\begin{tabular}{|c|c|c|c|c|}
\hline Type & Definition & No. & $\%$ & Sample quote \\
\hline $\begin{array}{l}\text { Social science } \\
\text { study report }\end{array}$ & $\begin{array}{l}\text { Uses social science empirical } \\
\text { methods to examine an } \\
\text { ethics-related, ELSI, or otherwise } \\
\text { morally salient issue in genetics } \\
\text { or genomics. }\end{array}$ & 108 & $17 \%$ & $\begin{array}{l}\text { "Objectives: We explored the opinions of } 40 \text { Black Americans regarding: } \\
\text { (i) what they thought most blacks and whites believe about genetic causes } \\
\text { for perceived race differences in human traits, and (ii) the impact of genetic } \\
\text { science on them, their families, and black people. } \\
\text { Methods: We conducted in-depth telephone interviews with } 40 \text { self-identified } \\
\text { Black men and women." }{ }^{33}\end{array}$ \\
\hline Broader ELSI & $\begin{array}{l}\text { Science, public health, or } \\
\text { clinical focus with at least some } \\
\text { discussion of ethical and/or ELSI } \\
\text { issues or a review or discussion }\end{array}$ & 239 & $37 \%$ & $\begin{array}{l}\text { "The field of mental health offers a valuable context in which to examine new } \\
\text { challenges presented by human genetic research databases to the legal, ethical, } \\
\text { and regulatory types for human genetic research." } 34\end{array}$ \\
\hline
\end{tabular}

of the ethical or ELSI issues

related to some area of genetics or genomics.

\begin{tabular}{|c|c|c|c|c|}
\hline Ethics focus & $\begin{array}{l}\text { Examines an issue within ethics } \\
\text { in which genetics or genomics } \\
\text { serves to exemplify, illustrate, or } \\
\text { complicate this ethics concept, } \\
\text { problem, or question. }\end{array}$ & 102 & $16 \%$ & $\begin{array}{l}\text { "This paper explores some of the challenges raised by human genetic } \\
\text { interventions for debates about distributive justice, focusing on the challenges } \\
\text { that face prioritarian theories of justice... Also examined are the implications } \\
\text { of germ-line genetic enhancements for intergenerational justice ..." }{ }^{35}\end{array}$ \\
\hline $\begin{array}{l}\text { Other normative } \\
\text { focus }\end{array}$ & $\begin{array}{l}\text { A specific normative focus other } \\
\text { than ethics (such as narrative } \\
\text { identity, race theory, religion/ } \\
\text { theology, science norms, or } \\
\text { intellectual property) is the } \\
\text { primary focus. }\end{array}$ & 127 & $20 \%$ & $\begin{array}{l}\text { "I . . . argue that a major contribution of theology to ethical reflection on } \\
\text { genetic research would be through discussion of ways of reading, } \\
\text { transmitting, and interpreting texts." } 36\end{array}$ \\
\hline $\begin{array}{l}\text { Policy } \\
\text { recommendation }\end{array}$ & $\begin{array}{l}\text { Primarily an evaluation, } \\
\text { recommendation, or statement } \\
\text { of genetics or genomics } \\
\text { research or practice policy } \\
\text { (law, regulation, or guideline). }\end{array}$ & 66 & $10 \%$ & $\begin{array}{l}\text { "[This paper] argues that, all things considered, the benefits of patenting } \\
\text { DNA outweigh the harms, although societies should adopt policies designed } \\
\text { to prevent or mitigate the harms associated with patenting. Some of these } \\
\text { policies include..." (ref. 37, p. 181) }\end{array}$ \\
\hline
\end{tabular}

ELSI, ethical, legal, and social implications.

and sample quotes from publications representing each type appear in Table 3. Each type is presented in more detail below along with significant correlations with particular topics and first-listed author fields of training, which are summarized in Table 4.

\section{Social science study report}

The social science empirical methods study reports predominately rely on qualitative methods, but quantitative methods are also well represented. Supplementary Figure S1 online details the methods reported in social science study report publications 
Table 4 Dominant topics and first-author fields for each publication type

\begin{tabular}{|c|c|c|c|c|c|c|}
\hline Type & $\begin{array}{l}\text { Dominant } \\
\text { topic(s) }\end{array}$ & $\begin{array}{c}\text { No. in type } \\
\text { (percentage } \\
\text { of type) }\end{array}$ & $\begin{array}{l}\text { No. in total } \\
\text { (percentage of } \\
\text { total), } N=642\end{array}$ & $\begin{array}{l}\text { Dominant } \\
\text { first-author } \\
\text { field }\end{array}$ & $\begin{array}{c}\text { No. in type } \\
\text { (percentage } \\
\text { of type) }\end{array}$ & $\begin{array}{c}\text { No. in total } \\
\text { (percentage } \\
\text { of total), } \\
N=642\end{array}$ \\
\hline Broader ELSI $(n=239)$ & Biorepository & $27(11 \%)$ & $49(8 \%)$ & Medicine & $71(30 \%)$ & $119(19 \%)$ \\
\hline Ethics focus $(n=102)$ & $\begin{array}{l}\text { Genetic } \\
\text { enhancement }\end{array}$ & $29(28 \%)$ & $44(7 \%)$ & Humanities & $62(61 \%)$ & $178(28 \%)$ \\
\hline Other normative focus $(n=127)$ & Genomics general & $23(18 \%)$ & $58(9 \%)$ & Humanities & $48(38 \%)$ & $178(28 \%)$ \\
\hline \multirow[t]{2}{*}{ Policy recommendation $(n=66)$} & Biorepository & $9(14 \%)$ & $49(8 \%)$ & Law & $26(40 \%)$ & $107(17 \%)$ \\
\hline & $\begin{array}{l}\text { Human subject } \\
\text { protection }\end{array}$ & $9(14 \%)$ & $24(4 \%)$ & & & \\
\hline
\end{tabular}

from our study. In terms of contributing community, it is not surprising that $41 \%$ of first-listed authors for these publications had advanced training in some area of social science. However, given the substantial methodological training required to conduct such a study, it may be more surprising that $35 \%$ of firstlisted authors had advanced training in either medicine or a science other than social science and that $14 \%$ had advanced training in the humanities.

The quote selected in Table 3 to illustrate the social science approach to ELSI research also illustrates the dominant topic within this type of publication, specifically genomic research and the public. Much of this research focused on the opinions of the public or of particular publics regarding specific areas of genomic science or of genomics generally. Although this topic was only $6 \%$ of the literature as a whole, it represented $22 \%$ of the social science publications.

Broad divergence with respect to whether and how social science study reports offer recommendations regarding the ELSI issues or topics addressed is particularly striking. In one report, the authors address morally salient issues regarding perceived quality of life in mothers of children with fragile $\mathrm{X}$ syndrome such as the positive impact of being a mother and stress associated with a lack of social support. Yet prescriptions offered by the authors were limited to projected future work, in particular that "in future studies with this population, researchers should emphasize the broader context of family well-being and adaptation to disability" (ref. 2, p. 172). In another report, the authors present a study of the views of at-risk children and parents about children's roles in decision making about enrollment in genetic susceptibility research. On the basis of their findings, the group offers a proposal for an informed consent process that "(a) gives parents and children sufficient opportunity to ask questions of the researcher(s) and to communicate with one another, and (b) gives children the opportunity to exercise their right to refuse participation without parental influence" (ref. 3, p. 260).

\section{Broader ELSI}

This type of research and scholarship discusses or enumerates the ELSI issues related to some aspect of human genetics or genomics. In the sample quote in Table 3, genetic databases (the dominant topic for this publication type) present "new challenges" for law, ethics, and regulations. Generally speaking, the broader ELSI approach to research and scholarship can be characterized as "downstream" in so far as the concerns are seen as following developments in the science, technology, and/or the practice of genetics or genomics. In keeping with this characterization, topics that are significantly dominated by a broader ELSI approach include personalized health interventions (personalized medicine, pharmacogenomics, and nutrigenomics), the introduction and use of genetics/genomics within clinical practice, whole-genome sequencing or genome-wide association studies, and gene transfer research.

Within the broader ELSI publication, ELSI analysis itself may become a kind of inquiry to be "integrated" into a larger scientific endeavor. Hence, "The HapMap has been an exemplar of integrated and proactive ELSI analysis in genetic variation research" (ref. 4, p. S8). In other examples, ethical, legal, social, and other issues or concerns may all be noted separately but addressed interchangeably. So, for example, "these benefits [of prenatal genetic testing] are, however, tempered by a series of complex ethical, legal and social risks ... These include: the risk of state intervention into private lives and the consequent loss in reproductive freedom; the risk of coercive testing emerging from medical paternalism; the risk of ambivalence in knowing whether prenatal testing should be offered for all conditions ..." (ref. 5, p. 67).

Although the broader ELSI publications sometimes specifically use the term "ethics" to identify the issues of concern (rather than either "ELSI" or "social" concerns), the ethical issues discussed can generally be characterized as morally salient practical problems, rather than issues arising within ethics as an area of study (such as would be a focus on how to understand respect for autonomy or whether to take a principlebased or virtue theory approach to justice). Hence, within the broader ELSI publication, "The Human Genome Project and related genetic research are exciting scientific quests that are also giving rise to significant ethical dilemmas and equity considerations ... [such as] is research on human cloning ethical, privacy of genetic and medical records, genetic discrimination, 
implications for public health programmes, unequal access to new but expensive therapeutic interventions ..." (ref. 6, p. 191).

In terms of contributing community, first-listed authors of the broader ELSI publications most commonly had advanced degrees in medical fields (30\%) or a science other than social science (26\%). In contrast, these fields are represented in 19\% and $18 \%$, respectively, of the publications overall. This finding may not be surprising, however, given that publications meeting the general description of broader ELSI may place emphasis on discussion of the genetics or genomics context or issue, addressing ethical or ELSI concerns only secondarily. Publications that simply raised ethical or ELSI issues but did not discuss them were not included in our study (see Figure 1); however, the extent to which publications focused on the ethical or ELSI issues in comparison with genomics or genetics ranged from a short discussion to the main focus of the publication.

\section{Ethics focus}

While broader ELSI publications take an issue, development, or practice in genetics or genomics as driving ethical or ELSI concerns, ethics-focus publications take as central an investigation within ethics. Very broadly, we might think of the ethicsfocus publication as "ethics upstream," with the ethical issues as perennial or primary, whereas genetics or genomics advances serve in different ways to help investigate, illuminate, or complicate these issues. In the sample quote in Table 3, the author is concerned to address how genetic interventions (including human enhancements) relate to theoretical concerns about justice. In contrast to the broader ELSI publications described above, the focus in this article is on theoretical concerns within ethics (the conceptual contours of different types of justice), while an issue related to advances in genomics research and/or practice (genetic intervention) serves as a context that can shed light on the theoretical debate.

The ethics-focus type includes both those publications that focus on specific ethical issues or topics and also those that focus on "meta" questions in ethics and bioethics, such as how to best address ethical issues arising in the context of genomics research or practices. For example, one author reflects on the value of a feminist approach to bioethics in the context of gene transfer writing, "I suggest that if traditional bioethics incorporates feminist understandings about gene transfer into its corpus, it has a better chance of serving the best interests of men and women equally" (ref. 7, p. 159).

Ethics-focus publications are most likely to be authored by individuals with advanced training in the humanities (61\%), which is not surprising, given that ethics is traditionally a branch of philosophy. However, not all humanities researchers and scholars writing this type of publication have degrees in philosophy; and there are also significant contributions from those with advanced training in law and the other sciences. Of particular interest is the striking fact that $28 \%$ of the ethics-focus publications address genetic enhancement, whereas this topic accounts for only $7 \%$ of publications overall.

\section{Other normative focus}

In contrast with ethics-focus publications, other normativefocus publications take some set of normative issues, questions, or concepts other than ethical as the primary focus. These concerns may be oriented, for example, to theology or religion, race theory, property rights including intellectual property, narrative identity, science norms, policy norms, or good governance. Although primarily adopting normative lenses other than ethics in their analyses, these publications hold a similar relationship to advances in genetics or genomics as the ethics-focus publications. Both approaches take as central their respective theoretical concerns or debates, whereas issues in genetics or genomics exemplify, illustrate, or complicate these types or sets of concerns.

The dominant topic within these publications was genomics generally, which is accounted for in large part by theological approaches, such as that in the sample quote in Table 3. However, publications taking up topics that were more specific, such as genetics/genomics and race or intellectual property, in which the issues are particularly amenable to framing as race theory or theoretical perspectives on ownership, respectively, were also common. Some authors working within these normative frameworks other than ethics addressed topics that also lend themselves easily to a broader ELSI analysis, such as pharmacogenomics or genetic testing. One pair of authors draw on "deliberative democracy and futures thinking" in order to offer an analysis of "how policy makers might manage the tensions and dilemmas they face by moving from an unstable, emergent policy arena [such as with pharmacogenetics] to a more stable one" (ref. 8, p. 533). Another author addresses genetic testing through the lens of narrative identity, writing, "This commentary responds to genetic testing of African ancestry through a series of personal narratives that reveal a complex, intimate, and individualized process of identity formation" (ref. 9, p. 142).

Not surprisingly, authors with advanced training in the humanities $(38 \%)$ and law $(23 \%)$ are the primary contributors to these normative publications primarily addressing frameworks other than ethics. While the humanities contributions are in part from those trained in theology, they also represent historians and philosophers, among others. Those writing from the perspective of law are contributing in large part to questions of good governance, appropriate models of intellectual property, and foundational questions in public policy. Another interesting set of contributors to this type of publication are authors trained in social sciences (19\%) writing from a theoretical (rather than empirical) perspective, for example, in addressing norms of kinship or feminist theory.

\section{Policy recommendation}

We classified a publication as a policy recommendation if its primary purpose was to evaluate, recommend, or state genetics or genomics research or practice policy. A minority of the policy recommendation publications are policy statements by institutional bodies regarding appropriate human genetics or genomics practices or research. For example, the Human Genome Organization Ethics Committee published a set of 
principles and recommendations regarding human genomic research in 2007. ${ }^{10}$ More common are policy recommendations put forward by individuals or coauthors in the context of an academic analysis or critique of a policy issue. The sample quote in Table 3 recommends a specific set of policies in response to a general policy issue (DNA patenting), and others offer analysis, critique, and/or recommendations regarding a particular policy or policy statement. For example, one group of authors offers a critique of the American College of Medical Genetics (ACMG) position on newborn screening, arguing that there were "limitations of the ACMG process" and that "programs are expanding rapidly, partly in response to the ACMG report, without the infrastructure in place to determine if the technology is bringing benefits or harms to children" (ref. 11, p. 1794).

Although publications serving primarily as policy recommendations or critiques are a small percentage of the ELSI literature overall, they dominate two particular topic areas: human subject protection and newborn screening. As we saw just above, there was a significant push for policies expanding newborn screening during the time period of this study, so it is perhaps not surprising that publications on the topic should primarily address policy considerations. Similarly, as human subject protection implies regulatory oversight, the focus on policy in these publications is also not surprising.

In terms of contributing community, it is interesting that while those with advanced training in the law dominate the publications that primarily serve as policy recommendations (accounting for 39\% of the contributions to this literature), authors with legal training are roughly equally as likely to write broader ELSI, other normative, or policy recommendations. The versatility of legal training between these types of publications, combined with the dominance of a particular type of publication, is unique among the fields of training.

\section{DISCUSSION}

As recommendations regarding ethical, legal, social, and policy questions associated with human genomics research, practices, and technologies are widely recognized as, in some sense, the primary business of ELSI research and scholarship, it may be quite surprising that policy recommendations as we have understood them account for such a small percentage of the literature overall. This might seem especially the case, given the particular emphasis put on policy work in both the 2003 and 2011 NHGRI vision statements (ref. 1, pp. 208-209; ref. 12, p. 840). In this context, it is important to emphasize that many other publications in our study contained policy recommendations, even though these recommendations were not the primary focus of the publication. At the same time, even those publications that primarily critique, discuss, or make recommendations regarding policies may not "directly inform" actual policies. Policy recommendations that take place as part of a largely academic discussion, for example, may have little or no impact on policy development or change, although particularly influential or popularized approaches may be more successful in this regard (ref. 13, p. 3). However, it is the "translational" work informing policy that is called for in the NHGRI statements and historically from the NHGRI and ELSI Research Program. ${ }^{15}$ In looking to the future, a continuing challenge will be determining how to position ELSI research relative to policy development.

In our study, we have understood policy recommendations as dealing specifically with laws, regulations, or institutional guidelines. While most ELSI publications have generally directive aims in the sense of offering suggestions or recommendations, not all of these are policy suggestions. Common within the ethics-focus type are prescriptions for moral action (e.g., regarding the "special moral problems in attempting to shape in advance the talents, preferences, and values of an individual with whom one expects to enter into a special kind of intimate relationship") (ref. 15, p. 99). Another kind of recommendation addresses neither moral action nor policy, but rather suggests a certain theoretical organization of the world. For example, an article may argue in favor of "a conception of genetic privacy with a strong relational component" (ref. 16, p. 737). For discussions of the future of ELSI research and scholarship, it will be helpful to keep in mind, in addition to policy guidance, a role for both general moral and theoretical guidance.

In the context of ELSI work, social science empirical studies may be seen as generating the "data" upon which reliable policy recommendations should be built. Within bioethics, generally there have been calls for more empirical work, in part because of perceived shortcomings with nonempirical approaches to bioethics (ref. 17-20, ref. 21, pp. 37-40, ref. 22). Indeed, the proportion of social science study reports found in our review coheres with the trend toward more inclusion of empirical work in bioethics generally. ${ }^{24-27}$ Yet, this increase in the proportion of empirical contributions, and arguments for more such contributions, have taken place without a clear resolution to the contested question of how empirical work should relate to, or inform, practical prescriptions and recommendations (including policy) (ref. 14, p. 11; ref. 27, p. 12; ref. 28, ref. 29) There is wide diversity within social science study reports in our study with respect to the strength and type of recommendations authors feel comfortable promoting regarding ethical, legal, social, or policy issues. As ELSI looks to the future, it should consider more critically and carefully, on one hand, what kinds of recommendations are best offered on the basis of what kinds of empirical claims and, on the other, what kinds of normative values already inform empirical work in ELSI.

In thinking toward the future, it is also important to recognize that the "downstream" model of raising and examining ELSI concerns arising with new or emerging genomic technologies, research, and practices has been the bread and butter of ELSI research. However, other models are available. Rather than focusing on the particular practical issues related to challenges in genomic science, we could focus on broader theoretical and normative concerns. Taking the NHGRI 2011 vision statement and specific ethics and other normative publications as comparison points, instead of looking at how to "design consent language that fully accounts for the broad utility that genomic data can 
offer ..." (ref. 1, p. 208), we might ask whether this broad utility could possibly cohere with the normative conditions under which informed consent is possible at all $;{ }^{30}$ or we might ask what fairness means in the context of genomic medicine ${ }^{32}$ instead of how to "ensure fair access to genomic medicine" (ref. 1, p. 210); or we could inquire how genomic medicine itself reinscribes race concepts as normative ${ }^{33}$ rather than how race relates to the "biology of disease" (ref. 1, p. 210). Meaningful answers to these deeper normative questions may ultimately have the greatest practical impact by helping to define the very parameters of useful action-guiding questions.

The inclusive understanding of ELSI literature and scholarship and the subsequent potential for engagement of the wider ELSI community is a strength of our study; however, a limitation is that we have not captured ELSI research and scholarship that either did not employ the search terms we used or did not appear in any of the other databases or websites that we consulted. Furthermore, we do not present a historical analysis of ELSI work, but rather a snapshot of the most recent ELSI work in the 5-year period prior to the start of our project. Some of the more common topics in our study no doubt reflect particular perceived ELSI challenges related to burgeoning research areas or related practices within genomics (e.g., increased development of biorepositories), whereas some of the lower-frequency topics represent either topics that had not been perceived to be of high salience for genomic science but currently are (e.g., return of results and whole-genome sequencing) or topics that were previously of high significance but, by the study period, were waning in terms of genomic research priorities (e.g., gene transfer research).

Yet, even this snapshot look at a feature of the ELSI literature as changeable as prevalent topics of inquiry can be highly informative, in particular in conjunction with other features of the literature and information about the contributing community. For example, as we saw, reflection on genomics generally is the most common ELSI topic. Although this topic might be dismissed as overly broad by those working in the genome sciences, it also correlates with publications, perhaps authored by a philosopher, theologian, or lawyer, specifically concerned with investigating foundational normative questions within ethics or other domains of normative inquiry. The flip side of addressing genomics generally while focusing on foundational normative questions is arguably a broad focus on "societal" or "ethical" issues while offering a focused consideration of a particular topic within genome science research, clinical practices, or technologies such as is a likely contribution to the ELSI literature from a genome scientist, biostatistician, or genetic counselor.

Put this way, ELSI looks like a community divided. But we know from the information gathered through our study that there is no clean breakdown of topics, training, and types of research and scholarship. ELSI is a field inhabited by authors with multiple advanced degrees and cross-training, who may engage in out-of-the-box thinking, and are perfectly willing to work on topics and projects that are of intellectual interest but not at the top of anyone's funding priorities (such as genetic enhancement). Despite clear trends and correlations documented by our investigation, it is no more the case that all those writing about theoretical issues in ethics are philosophers than it is true that all genome scientists are addressing ethical issues as only of secondary interest. Similarly, while so-called "normative" work in ELSI is frequently an inquiry into the ethical "implications" of a particular advance in genomics, or, less frequently, an investigation of the appropriate conceptualization of a theoretical construct within ethics, it may also be exemplified by a social scientist working in kinship theory or a science studies $\mathrm{PhD}$ investigating the norms of social science. These opportunities to "buck the trends" in ELSI that are evident from a look at the field's most recent past may show as much, or more, about the potentiality of ELSI's future as the strong imprinteur of certain research and scholarship types and significant correlations with topics and fields of training that we have documented.

\section{SUPPLEMENTARY MATERIAL}

Supplementary material is linked to the online version of the paper at http://www.nature.com/gim

\section{ACKNOWLEDGMENTS}

We are grateful for the support of the UNC Center for Genomics and Society, which has funded this research through an $\mathrm{NIH}$ Centers for Excellence in ELSI Research grant (number 1P50 HG004488-01) to Gail Henderson (PI). We thank Warren Whipple, Martha King, and Allen Buansi for their assistance in coding. We also thank the UNC Odum Institute as well as Gail Henderson, Debra Skinner, and Michele Easter for advice regarding research methods. Finally, we thank Eric Juengst and Nancy King for substantive helpful discussions regarding the field of ELSI research.

\section{DISCLOSURE}

The authors declare no conflict of interest.

\section{REFERENCES}

1. Green ED, Guyer MS; National Human Genome Research Institute Charting a course for genomic medicine from base pairs to bedside. Nature 2011;470:204-213.

2. Wheeler AC, Skinner DG, Bailey DB. Perceived quality of life in mothers of children with fragile X syndrome. Am J Ment Retard 2008;113:159-177.

3. Geller G, Tambor ES, Bernhardt BA, Fraser G, Wissow LS. Informed consent for enrolling minors in genetic susceptibility research: a qualitative study of at-risk children's and parents' views about children's role in decision-making. J Adolesc Health 2003;32:260-271.

4. Cho MK, Sankar P. Forensic genetics and ethical, legal and social implications beyond the clinic. Nat Genet 2004;36(11 Suppl):S8-12

5. Ekberg M. Maximizing the benefits and minimizing the risks associated with prenatal genetic testing. Health, Risk and Society 2007;9:67-81.

6. Phua K.-L. The Human Genome Project and genetic research: what are the implications for ethics and equity? Critical Public Health 2004;14: 191-200

7. Tong R. Traditional and feminist bioethical perspectives on gene transfer: is inheritable genetic modification really the problem? In: Rasko J, O'Sullivan G, Ankeny R (eds). The Ethics of Inheritable Genetic Modification: A Dividing Line? Cambridge University Press: Cambridge, 2006:159-171.

8. Ling T, Raven A. Pharmacogenetics and uncertainty: implications for policy makers. Stud Hist Philos Biol Biomed Sci 2006;37:533-549. 
9. Baylis F. Blacks as me: narrative identity. Dev World Bioeth 2003:3:142-150

10. HUGO Ethics Committee. HUGO statement on pharmacogenomics (PGX): solidarity, equity and governance. Genomics, Society and Policy 2007;3: 44-47.

11. Botkin JR, Clayton EW, Fost NC, et al. Newborn screening technology: proceed with caution. Pediatrics 2006;117:1793-1799.

12. Collins FS, Green ED, Guttmacher AE, Guyer MS; US National Human Genome Research Institute. A vision for the future of genomics research. Nature 2003:422:835-847.

13. Sharp RR, Yudell MA, Wilson SH. Shaping science policy in the age of genomics. Nat Rev Genet 2004;5:311-316.

14. Juengst ET. The Human Genome Project and bioethics. Kennedy Inst Ethics J 1991:1:71-74.

15. Wasserman DT. My fair baby: what's wrong with parents genetically enhancing their children? In: Gehring VV (ed). Genetic Prospects: Essays on Biotechnology, Ethics, and Public Policy. Rowman and Littlefield: Lanham, 2003:99.

16. Suter SM. Disentangling privacy from property: toward a deeper understanding of genetic privacy. George Washington Law Rev 2004;72:737-814

17. Halpern SD. Towards evidence based bioethics. BMJ 2005;331:901-903.

18. Hedgecoe AM. Critical bioethics: beyond the social science critique of applied ethics. Bioethics 2004;18:120-143.

19. Hoffmaster B. Can ethnography save the life of medical ethics? Soc Sci Med 1992;35:1421-1431.

20. DeVries R, Conrad P. Why bioethics needs sociology. In: DeVries R, Subedi $J$ (eds). Bioethics and Society: Constructing the Ethical Enterprise. Prentice Hall: Englewood Cliffs, 1998:233-257.

21. Rosenberg CE. Meanings, policies, and medicine: on the bioethical enterprise and history. Daedalus 1999;128:27-46.

22. Jacoby L, Siminoff LA. Introduction. In: Jacoby L, Siminoff LA (eds). Empirical Methods for Bioethics: A Primer. JAI Press: San Diego, 2008:1-10.

23. Jacoby L, Siminoff LA eds. Empirical Methods for Bioethics: A Primer. JAI Press: San Diego, 2008.
24. Sugarman J, Faden R, Weinstein J. A decade of empirical research in medical ethics. In: Sugarman J, Sulmasy DP (eds). Methods in Medical Ethics, 2nd edn. Georgetown University Press: Washington, D.C., 2010:21-34.

25. Sulmasy DP, Sugarman J. The many methods of medical ethics. In: Sugarman J, Sulmasy DP (eds). Methods in Medical Ethics, 2nd edn. Georgetown University Press: Washington, D.C., 2010:3-19.

26. Borry P, Schotsmans P, Dierickx K. Empirical research in bioethical journals. A quantitative analysis. J Med Ethics 2006;32:240-245.

27. Nelson JL. Moral teachings from unexpected quarters. Lessons for bioethics from the social sciences and managed care. Hastings Cent Rep 2000;30: 12-17.

28. Hoffmaster B, Hooker C. How experience confronts ethics. Bioethics 2009;23:214-225.

29. Haimes E. What can the social sciences contribute to the study of ethics? Theoretical, empirical and substantive considerations. Bioethics 2002;16: 89-113.

30. O'Neill O. Some limits of informed consent. J Med Ethics 2003;29:4-7.

31. Farrelly C. Genes and equality. J Med Ethics 2004;30:587-592.

32. Brewer RM. Thinking critically about race and genetics. J Law Med Ethics 2006:34:513-9, 480

33. Sheldon JP, Epstein Jayaratne T, Feldbaum MB, DiNardo CD, Petty EM. Applications and implications of advances in human genetics: perspectives from a group of Black Americans. Community Genet 2007:10:82-92.

34. Mc Fleming J. The governance of human genetic research databases in mental health research. Int J Law Psychiatry 2007;30:182-190.

35. Farrelly $C$. Justice in the genetically transformed society. Kennedy Inst Ethics J 2005:15:91-99.

36. Muers R. Reading texts between generations: a proposal concerning theological engagement with genetic research. Scottish Journal of Theology 2004;57:466-478.

37. Resnik DB. Are DNA patents bad for medicine? Health Policy 2003;65: 181-197. 